\title{
O Sistema de Yalta como condicionante da política internacional do Brasil e dos países do Terceiro Mundo
}

\author{
PAULOG. FAGUNDES VIZENTINI*
}

\section{Introdução}

Transcorridos cinqüenta anos da Conferência de Yalta e encerrado o ciclo histórico regido pelo sistema internacional nela estruturado, faz-se necessário repensar estas questões sem o envolvimento político, ideológico, pessoal e sentimental que caracterizaram a maioria das análises até o presente. Por outro lado, Yalta pode ser enfocada num sentido restrito ou amplo. De forma restrita, Yalta é considerada meramente como um acordo diplomático que configurou um sistema internacional bipolar antagônico, opondo o Oeste capitalista ao Leste socialista, blocos liderados respectivamente pelas superpotências americana e soviética. Ainda dentro deste enfoque, Yalta é analisada apenas em relação ao cenário europeu, generalizando-se esta percepção para o sistema internacional como um todo. Assim, a divisão da Europa passa a ser entendida como a divisão do mundo.

Acreditamos que este sentido restrito de Yalta encobriu, historicamente, uma outra dimensão mais ampla da questão, que precisa ser resgatada. Yalta não propiciou somente um conflito Oeste-Leste, nem a Europa foi seu único cenário. O chamado Sistema Bipolar de Yalta teve profundas implicações para a América Latina e para a periferia colonial e semicolonial afro-asiática, regiões que ficariam conhecidas como Terceiro Mundo. A posição internacional dos países do Sul dentro do Sistema de Yalta nos revela não apenas um confronto entre os

Rev. Bras. Polít. Int. 40 (1): 5-17 [1997].

* Professor Titular de História Contemporânea e Relações Internacionais na Universidade Federal do Rio Grande do Sul (UFRGS). 
dois blocos antagônicos, mas também uma poderosa estrutura de dominação das potências do Norte sobre o Sul. A subordinação dos países periféricos de um dos sistemas em relação à potência dominante de seu próprio bloco tornou-se uma contradição importante ao longo da evolução do Sistema de Yalta. Neste sentido, a percepção de Yalta pelos países do Terceiro Mundo difere significativamente das interpretações correntes no hemisfério Norte.

No caso especificamente brasileiro, embora o país estivesse preso exatamente aos mesmos condicionantes dos demais Estados latino-americanos, uma parta da elite dirigente considerava que éramos aliados privilegiados de Washington. Tal status idealizado levava-os a crer que o país receberia um tratamento distinto do dispensado ao resto do continente. Apostando na política de segurança nacional antiesquerdista, no alinhamento diplomático com a potência reitora e na economia liberal, aberta e exportadora, este segmento será frustrado e ultrapassado por outro, que possuía uma leitura identificada com os postulados acima expostos.

\section{A Conferência de Yalta e seu contexto histórico}

As questões sobre a reorganização Pós-Guerra foram tratadas nas conferências de Teerã, Moscou, Yalta e Potsdam, ao longo das quais transita-se da colaboração entre aliados contra o Eixo a divergências entre os aliados ocidentais e os soviéticos, que estavam ligadas às origens do conflito denominado Guerra Fria. Em Yalta (balneário soviético do mar Negro), Churchill, Roosevelt e Stalin reuniram-se no início de fevereiro de 1945 e referendaram a fixação da fronteira soviético-polonesa na Linha Curzon e a entrega dos territórios alemães ao leste dos rios Oder-Neisse à Polônia, como indenização pela destruição e pelo genocídio desencadeados pelos nazistas. Além disso, alguns membros do governo polaco exilado em Londres formariam parte de um governo de coalizão, dentro do Comitê de Lublin (de esquerda e pró-soviético). Na Iugoslávia também elementos do governo conservador deveriam fazer parte do governo de Tito (apoiado pela URSS). Foi acordado ainda que a Alemanha não seria partilhada, embora, a curto prazo, as quatro potências aliadas (EUA, URSS, Grã-Bretanha eFrança) dividissem o país em zonas de ocupação, até a conclusão do processo de desnazificação, quando, então, o país recuperaria sua soberania e unidade (a Guerra Fria daria outro rumo a esta questão). Além disso, Roosevelt obteve da URSS o compromisso de entrar em guerra contra o Japão na Manchúria três meses após a capitulação alemã, com o fim deneutralizar o núcleo militar eindustrial japonês estabelecido na Manchúria, de difícil acesso para os norte-americanos. 
A Conferência de Yalta foi o ponto alto de colaboração entre EUA e URSS, e demonstrou o declínio da Grã-Bretanha como potência mundial. O significado maior, implícito na Conferência, foi a chamada divisão de esferas de influência. Alguns historiadores (saudosistas do velho domínio europeu) falam de uma "partilha do mundo" em Yalta, entre EUA e URSS. O que houve, concretamente, foi um acordo segundo o qual os países limítrofes com a URSS na Europa não deveriam possuir governos anti-soviéticos, como forma de garantir suas fronteiras ocidentais (foi através destes países, e com apoio de alguns deles, que os nazistas a invadiram). Tudo mais foi decorrência da Guerra Fria. Adireita autoritária, através de seus historiadores, insistiu posteriormente que um Roosevelt "velho e doente” fora fraco nas negociações, "entregando a Europa oriental a Stalin”, além de “introduzir a Rússia no Extremo Oriente”. Esta interpretação é típica dos dias de Guerra Fria, pois no início de 1945 os americanos insistiam na necessidade da URSS destruir os exércitos japoneses do norte da China, para apressar e facilitar a derrota nipônica.

Quanto à “concessão” do leste europeu aos soviéticos, é preciso ter em conta que estes haviam libertado e/ou ocupado a região (nela encontravase o Exército Vermelho) e que as guerrilhas lideradas pelos comunistas nacionais eram muito fortes na maioria dos países da região (inclusive na Iugoslávia e Albânia, haviam libertado praticamente sozinhas seus países). Ou seja, estes já controlavam de fato a região. Além disso, o reconhecimento da influência soviética na estreita faixa de países pobres da Europa centrooriental, enquanto o resto do planeta permanecia sob o domínio do capitalismo (em particular norte-americano), evidencia o exagero da expressão "partilha do mundo". Mesmo em termos de Europa, esta “partilha” não teria termo de comparação. O que veio a ser profundamente irônico foi que a área de influência soviética possuía uma esquerda relativamente débil, enquanto que na França e na Europa mediterrânea os comunistas constituíam uma força expressiva e auto-sustentada. Assim, a presença soviética no leste contrariava o status quo e produzia consideráveis conflitos, enquanto a presença norteamericana no oeste defendia os interesses estabelecidos, não resultando em maiores atritos.

O clima da Conferência de Potsdam (arredores de Berlim, de 17 de julho a 2 de agosto de 1945) já foi bem diferente. Truman representava agora os EUA e tinha uma posição bastante rígida com a URSS. A Grã-Bretanha realizou eleições durante a Conferência, e Churchill foi substituído pelo trabalhista Attlee. Nela, foi pormenorizado o controle aliado sobre a Alemanha, ojulgamento dos criminosos de guerra nazistas, bem como as reparações de guerra; foi ratificada a linha Oder-Neisse como fronteira germano-polonesa e o pedido da 
entrada da URSS na guerra contra o Japão. Além disso, Truman informou Stalin sobre a existência da Bomba Atômica, sem explicar-lhe o potencial da mesma.

Acima de tudo, a Conferência de Potsdam explicita uma alteração política fundamental, ocorrida desde o início de 1945. E esta mudança profunda não foi percebida imediatamente pelos soviéticos. Stalin e o Comitê Central do PCUS estruturaram toda a estratégia política contando com a política de Roosevelt, sem atentar para a luta pelo poder então existente na cúpula americana. A confiança que tinham no presidente foi estendida a todo o governo dos EUA. O bombardeio de Dresden foi um sinal de uma nova política. Com a morte de Roosevelt, assumiu o vice-presidente Truman, um político pouco expressivo do interior que, por suas limitações, ligou-se ao emergente Pentágono e, dentro deste, ao grupo do bombardeio estratégico. Estes grupos ampliariam imensamente sua influência sobre o governo quando a Bomba Atômica entrou em cena (Dresden havia sido realmente uma avant-première do que estava por vir). O General Groves, responsável pelo Projeto Manhatan (produção da Bomba A) afirmou em 1942, em plena vigência da aliança EUA-URSS, que esta seria uma arma importante contra a União Soviética! No mesmo ano, Churchill elaborou um Memorandum Secreto, em que afirmava que assim que o Eixo deixasse de constituir uma ameaça, os anglo-saxões deveriam recordar que a URSS representava o "verdadeiro inimigo”. Ora, em 1945 a derrota do Eixo era certa e a luta só prosseguia devido à obstinação suicida da elite nazista. A Alemanha e o Japão não representavam mais perigo e a "verdadeira política" podia sair à luz do dia. Mas somente com o bombardeio nuclear de Hiroshima e Nagasaki, Stalin se dará conta da amplitude da mudança ocorrida.

AConferência de Potsdam sinalizou oinício dedivergências explícitas entre os EUA e a URSS, a afirmação de ambos como as novas superpotências mundiais (embora a União Soviética, devastada e sem arma atômica, tivesse apenas um poder defensivo naquele momento) e o declínio da Europa e do sistema de equilíbrio de poder, agora substituído por uma política internacional bipolar (embora os “blocos” ainda não estivessem constituídos). Encarada pelo prisma de Washington, que era o protagonista detentor da iniciativa estratégica, Potsdam retificou Yalta, iniciando a redução da legitimidade reconhecida a Moscou no leste europeu e impedindo a aplicação das regras de Yalta à Ásia Oriental. Se os Estados Unidos, por um lado, continuavam afirmando o papel protagônico da URSS no Sistema Internacional enquanto superpotência(como forma de obstaculizar o ressurgimento das potências européias), por outro, tratavam de conter sua atuação dentro de limites estritos, enquanto exageravamum “perigosoviético”(visandoenquadrardeformasubordinada as potências européias e a legitimar sua ascendência sobre os países periféricos). 


\section{A América Latina e o Brasil sob o Sistema de Yalta}

Para uma avaliação do impacto de Yalta sobre as regiões periféricas que viriam a ser denominadas como Terceiro Mundo, bem como da percepção deste sobre o novo sistema internacional, é preciso inicialmente observar o mapa político do mundo em 1945, cuja composição refletia-se na Organização das Nações Unidas (ONU). Os países independentes localizavam-se em sua maioria na Europa e na América, existindo alguns na Ásia e apenas quatro na África. É preciso levar-se em conta que os Estados realmente protagônicos do grande jogo internacional encontravam-se apenas na Europa e na América do Norte, na medida em que na Ásia Oriental encontravam-se dois Estados importantes mas arrasados, um pela guerra mundial (o Japão) e outro também pela guerra civil (a China), e que a América Latina possuía uma inserção internacional fortemente condicionada pela diplomacia norte-americana.Assim, a grande política mundial era protagonizada por um número extremamente limitado de atores. Neste contexto, a América Latina constituía uma zona de países independentes mas fortemente caudatária da Política Externa de Washington, enquanto a África e a Ásia formavam um mundo colonial relativamente fechado, ainda vinculado à Europa.

Em relação à América Latina, o que está implícito no Acordo de Yalta é que todo o subcontinente deveria ficar sob controle norte-americano, sem uma atuação autônoma no cenário internacional. O problema, para os Estados Unidos, é que existiam fortes tendências nacionalistas nos grandes países da região, geralmente associadas a projetos autônomos de desenvolvimento, como no Brasil de Vargas, no México e na Argentina de Perón, estando esta última ainda fortemente vinculada à Europa. Isto ocorria num contexto em que o fim da guerra eliminava o fator agregador pró-norte-americano representado pela aliança contra o Eixo (da qual a Argentina manteve certa distância), além de que, economicamente, os grandes países do continente haviam se fortalecido durante a guerra e em virtude dela, preparando-se para lançar uma nova etapa de desenvolvimento industrial, o que logicamente não interessava aos Estados Unidos. Para completar, este país encontrava-se mais preocupado e envolvido nas “regiões quentes da Guerra Fria” que se iniciava, como desdobramento lógico de Yalta, não podendo desenvolver uma política mais ativa na ÍberoAmérica para dar continuidade ao enquadramento da região ao sistema internacional regido pelos EUA, e que vinha sendo desenvolvida desde a ascensão de Roosevelt através da Política de Boa Vizinhança e da aliança anti-hitleriana. 
O final da Segunda Guerra Mundial, neste sentido, colocava para Washington a necessidade de reafirmar sua hegemonia sobre a Íbero-America, problema cuja solução encontrava-se na aplicação do Sistema de Yalta ao subcontinente. Os perigos contidos na Guerra Fria para a região foram de tal forma exagerados, que hoje nos surpreendemos como um discurso político tão simplista e descontextualizado pode servir de base, com eficácia, para uma estratégia de tão longo alcance. Com o fim do suposto "perigo nazista-alemão", introduziu-se na mídia e na vida política um discurso maniqueísta que ressaltava a configuração de uma ainda maior “ameaça comunista-soviética”, como forma de forjar uma nova legitimidade para o alinhamento do continente em torno do “protetor norte-americano”.

Sob o signo de Yalta, foi condicionado o conteúdo da Doutrina Monroe, com a criação de organizações internacionais especificamente destinadas a enquadrar o continente à Pax Americana, o Tratado Interamericano de Assistência Recíproca (TIAR, ou Pacto do Rio de Janeiro), um instrumento militar criado em 1947, destinado à ajuda mútua em caso de "ameaça externa" a qualquer país do continente, e a Organização dos Estados Americanos-OEA, criada em 1948 como organização política, com sede em Washington. A Escola Superior de Guerra, dentro de cada país, e a Escola do Panamá, criadas na mesma época, com suas teorias geopolíticas, com a assistência militar e o apoio a golpes de Estado e regimes ditatoriais, completam o quadro dos novos instrumentos de poder dos Estados Unidos sobre o subcontinente. Entre outros aspectos, Yalta significava para a América Latina um tratamento diferente do que os EUA concediam à Europa, onde este país defendia a democracia e o "mundo livre".

No plano econômico também ficava evidente a diferença entre a aplicação do sistema de Yalta em relação à América Latina e ao velho continente. Enquanto os Estados Unidos brindavam a Europa com o Plano Marshall, que inclusive reconstruiu rapidamente os países do antigo Eixo, na Íbero-América enfatizavam as questões de segurança (principalmente interna), enquanto esta tentava orientar a pauta de cooperação para o tema do desenvolvimento. Sob o signo de Yalta, Washington encarou a região como reserva econômica, tratando-a com certo descaso. Não apenas os EUA procuravam mantê-la subordinada enquanto consumidora de produtos manufaturados, como especialmente tentavam obstaculizar seu desenvolvimento, para que uma possível industrialização latino-americana não viesse a consumir as reservas materiais existentes. Evidência disto e dos instrumentos empregados para lograr tal fim foi que a Casa Branca, apoiando-se nos organismos 
econômicos internacionais sob seu controle, forçaram os países latino-americanos a adotar um liberalismo econômico ortodoxo que nos próprios Estados Unidos já havia deixado de existir desde a Grande Depressão.

Para completar o quadro, Washington obstaculizava mesmo uma mínima iniciativa de autonomia diplomática por parte da América Latina, fechando-a para qualquer possibilidade de barganha. Neste contexto, os EUA não apenas exigiam um alinhamento automático e sem discussão do continente na Guerra Fria, como propositalmente tratavam qualquer manifestação de nacionalismo desenvolvimentista, mesmo associado ao capital internacional, como expressão de "comunismo". Não apenas governos nacionalistas, progressistas e desenvolvimentistas foram atacados sob a acusação de cripto-fascismo ou de comunizantes (Vargas no Brasil, Arbenz na Guatemala, Perón na Argentina, entre outros), como em 1947 os Partidos Comunistas foram fechados ao longo de todo o continente, justificando-se tal medida como combate à subversão social, justamente no momento em que estes partidos defendiam as burguesias nacionais na busca do desenvolvimento industrial!

Neste contexto, o Brasil constituiu um caso extremamente interessante. A diferença em relação à América Hispânica era que o Brasil pretendia ocupar uma posição diplomático-estratégica de aliado privilegiado dos Estados Unidos. Tal percepção, confrontada com a realidade da política de Washington para o continente, resultou numa crescente frustração. Tanto mais grave, porque a Política Externa brasileira foi se tornando, como salientou Amado Cervo, uma Política Externa para o Desenvolvimento. Assim, as relações com os EUA possuíam uma importância crucial para o Brasil, muito além do mero jogo de influência, prestígio e liderança com relação ao resto da América Latina.

O desenvolvimento industrial doBrasil foise tornando o projeto estratégico de um segmento da elite brasileira (apoiado por outros setores sociais) e encontrou suporte ideológico-programático no nacionalismo do ISEB (Instituto Superior de Estudos Brasileiros), e confrontou-se cada vez mais com a política da Casa Branca para a região baseada no Sistema de Yalta. Esta política, no Brasil, encontrava suporte no pensamento geopolítico da ESG (Escola Superior de Guerra) e num segmento civil que apostava na agroexportação e nas “indústrias naturais”, dentro da concepção econômica liberal. A leitura da realidade internacional por parte deste grupo identificava-se plenamente com o Sistema de Yalta, mas equivocava-se ao pensar que, através de um alinhamento automático com os Estados Unidos, seria tratada de forma privilegiada, como se fizesse parte dos países do Norte. 
As vicissitudes do desenvolvimento brasileiro até 1964 propiciaram o contínuo reforço do argumento dos nacionalistas e, por consequência, o questionamento do que a diplomacia brasileira viria futuramente denominar de “congelamento do poder mundial”, implícito no Sistema de Yalta. Isto seria incompreensível se não se levasse em consideração o fato de que tal sistema bloqueava o desenvolvimento econômico nacional, o que no caso do Brasil revelou-se decisivo. Por isso a diplomacia do Itamaraty, através da Política Externa Independente (1961-64), buscou romper com as limitações de Yalta através da multilateralização e da mundialização das relações exteriores do país, num momento em que este sistema apresentava os primeiros sinais de desgaste.

\section{Yalta e a descolonização asiático-africana}

A situação do mundo periférico submetido ao colonialismo europeu, por outro lado, era significativamente diferente nas primeiras fases de vigência do Sistema de Yalta. Este condenava abertamente a persistência dos vínculos coloniais na Ásia e na África, tanto através da diplomacia de cada uma das superpotências protagônicas quanto das Nações Unidas. Neste aspecto, não existe inicialmente grandes contradições entre EUA e URSS, inclusive porque até a década de 1950 Moscou tinha em relação a esta questão uma atitude unicamente retórica e principista.Assim, todo o mundo colonial era considerado implicitamente uma região sob influência americana, seja pela ascendência sobre as metrópoles européias, seja por uma certa anuência soviética ao apoio de Washington à ascendência dos povos coloniais à independência. Neste sentido, para estes últimos a política de Yalta, exercida mais diretamente através dos EUA, constituía um fator positivo e progressista.

Mesmo quando a Ásia Oriental foi sacudida pelas vitórias comunistas na China e logo em seguida no Vietnã, bem como pela Guerra da Coréia, os Estados Unidos mantiveramuma política progressista, que favoreceu as elites desta região. Reformas agrárias e de base bastante radicais foram promovidas e ativamente apoiadas por Washington, conduzindo países como Japão, Taiwan e Coréia do Sul no rumo do desenvolvimento. Masépreciso reconhecer que esta região foi tratada a partir dos anos 50 como uma "fronteira quente da Guerra Fria”, da mesma maneira que a Europa a partir de 1945, não se podendo generalizá-la como “percepção do Sul”. O que a Ásia Oriental manteve em comum com a América Latina foi a tendência de seus regimes ditatoriais serem apoiados pelos EUA. Estes regimes no leste asiático, entretanto, condicionaram sua subordinação política ao apoio americano a seu desenvolvimento econômico, o que a América 
Latina não conseguiu. No que tange à Ásia, esta postura foi uma consequência da pujança das revoluções socialistas de base nacional, as quais seriam capazes de desequilibrar o status quo regional. De qualquer maneira, é importante registrar a flagrante contradição com os países da América Latina, que já possuíam 130 anos de vida independente, e em relação aos quais foi desenvolvida uma política de alianças que favorecia a permanência de forças socialmente reacionárias e economicamente descomprometidas com o desenvolvimento.

A evolução do processo de descolonização, contudo, alterou os dados do problema, fazendo com que a Ásia e a África adotassem posturas semelhantes às da Íbero-América quanto ao significado de Yalta. Na medida em que as independências avançavam, as jovens nações afro-asiáticas vivenciavam com maior intensidade a necessidade do desenvolvimento econômico. Assim, a Conferência de Bandung, se por um lado ainda se preocupa com a necessidade do avanço do processo de descolonização, já aborda de forma clara a questão do desenvolvimento e a oposição à política de esferas de influência configurada em Yalta, bem como a corrida armamentista dela decorrente.

Bandung não apenas marcou um desafio para Yalta, ao enfatizar o neutralismo e o não-alinhamento, bem como da prioridade dada ao desenvolvimento (que implicava em estabelecer um novo sistema de relações interna-cionais superador das limitações impostas por Yalta), como ainda configurou novas opções de ação para a América Latina. O terceiromundismo propiciava um suporte político-ideológico aos regimes populistas latino-americanos na defesa de reformas de base como via para o desenvolvimento. Isto levou a uma contestação aberta à hegemonia norte-americana e à formação de uma esquerda terceiromundista revolucionária e autônoma, que chega ao poder em Cuba em 1959, configurando um profundo desafio ao Sistema de Yalta, ao questionar a hegemonia dos EUA numa região que era internacionalmente reconhecida como sua área de influência (mesmo pela URSS). Se o processo de descolonização que conduziu à formação do Terceiro Mundo e do Movimento dos Países Não-Alinhados alterou as bases internacionais sobre as quais se estruturou o Sistema de Yalta, a Revolução Cubana representou o primeiro sinal de desgaste deste sistema.

\section{Conclusão: Yalta vista pelo Sul}

OAcordo de Yalta originou um Sistema Internacionalbipolarprotagonizado pela superpotência norte-americana e pela soviética, no qual a iniciativa estratégica cabia à primeira. Tratava-se tanto de um confronto entre dois sistemas sociais antagônicos, como de um conjunto de regras informais que regulava este 
antagonismo, restringindo seu potencial desestabilizador. Do lado soviético, isto permitia a sobrevivência do que Mike Davis chamou de um "agregado de socialismos numsó país”, dentro de umbloco de alcance unicamente regional (pelo menos até o início dos anos 60).

Para os norte-americanos, Yalta legitimava sua ascendência sobre todos os países capitalistas e sobre a economia mundial, em face de um exagerado “perigo externo”. Os capitalismos existentes até a Segunda Guerra Mundial, pólos antagonistas e concorrenciais da economia internacional, davam lugar com Yalta a um capitalismo único, coordenado e relativamente unificado pelos Estados Unidos. Se para os europeus Yalta pareceu sempre significar a divisão do mundo, para os povos latino-americanos, e posteriormente afro-asiáticos, Yalta parecia muito mais uma estratégia de dominação de Washington sobre o Terceiro Mundo, uma vez que apenas a Europa Ocidental e a Ásia Oriental capitalista tiravam algum proveito deste sistema de relações internacionais.

Para a maioria esmagadora dos países do Sul periférico, a "ameaça soviética” constituíauma possibilidaderemotíssima, que era evocada porWashington exageradamente como um perigo iminente, visando enquadrá-los politicamente à Pax Americana. Percebiam gradativamente que os EUA eram o centro de um sistema mundial (do qual faziam parte), enquanto a URSS dominava apenas um bloco regional, e que o conflito bipolar afigurava-se não apenas como um enfrentamento entre dois blocos, masespecialmente comoum complexomecanismo de subordinação do Sul pelo Norte. Mesmo a “ameaça comunista” interna só era um fator significativo em raros países e, ainda assim, as elites nacionais percebiam o fenômeno geralmente como independente da vontade do Kremlin, que preferia mais ter uma Embaixada real num país do Terceiro Mundo a apoiar movimentos que, virtualmente, poderiam criar um regime simpatizante.

Embora os governos do Terceiro Mundo geralmente simpatizassem com os postulados sociais defendidos pela potência americana (como a defesa da propriedade privada) na busca do desenvolvimento econômico por parte destes, 0 relacionamento com os Estados Unidos resultava frustrante. O Sistema de Yalta parecia-lhes uma camisa de força que obstaculizava os processos de modernização e desenvolvimento, confinando-os a um atraso que favorecia justamente a potência “protetora” e defensora do "mundo livre”. Mas o discurso dominante na política e na mídia ocidental seguia generalizando a dimensão européia de Yalta para o conjunto do sistema mundial. Este fenômeno acabou, ideologicamente, por ocultar Yalta como instrumento de dominação dos Estados Unidos sobre sua periferia, tal como era vivenciada pelos países do Sul em sua busca de modernização edesenvolvimento. 
No caso brasileiro, a leitura que o segmento nacional-desenvolvimentista da elite diplomática, política e empresarial fazia da Política Exterior e do sistema internacional era fortemente condicionada por este tipo de percepção. À medida em que este segmento logrou impor-se como definidor da agenda externa, o esforço diplomático do Brasil passou a orientar-se para a busca de estratégias de inserção internacional que contornassem as limitações impostas pelo Sistema de Yalta. Embora o país não tivesse condições e mesmo intenções de desafiar a potência hegemônica em seu esforço de multilateralizar e mundializar suas relações exteriores (como forma de apoiar o processo de desenvolvimento industrial substitutivo de importações), procurou abrir novos espaços de cooperação, chegando neste caminho a ponto de estabelecer relações com a superpotência adversária. Também para a Política Externa brasileira, o Sistema de Yalta encobria um conflito Norte-Sul, que lentamente emergiu, obrigando o país a buscar uma maior autonomia no quadro das relações internacionais.

Junho de 1997

\section{Bibliografia}

ARON, Raymond. República Imperial: os Estados Unidos no mundo do pós-guerra. Rio de Janeiro: Zahar, 1975.

BOERSNER, Demetrio. Relaciones internacionales de America Latina.Caracas: Nueva Sociedad, 1987.

CERVO, Amado (Org). O desafio internacional; a política externa brasileira de 1930 a nossos dias. Brasília: UnB, 1994.

CHHABRA, H. K. Relations of Nations. Delhi: Surjeet, 1987. 3 vols.

CONTE, Arthur. Yalta, ou a partilha do mundo. Rio de Janeiro: Biblioteca do Exército, 1986.

DAVIS, Mike. “O imperialismo nuclear e dissuasão extensiva”, in THOMPSON, Edward et alli. Exterminismo e Guerra Fria. São Paulo: Brasiliense, 1985.

DUNBABIN, J. P. D. The Post-imperial age: the great powers and the wider world. London/New York: Longman, 1994.

DURAND, Yves. Naissance de la Guerre Froide: 1944-1949. Paris: Messidor/Temps Actuels, 1984.

DUROSELLE, J.-B. Histoire diplomatique de 1919 à nos jours. Paris: Dalloz, 1978.

FONTAINE, André. Histoire de la Guerre Froide. Paris: Fayard, 1975. 2 vols.

GRIMAL, Henri. La décolonisation de 1919 à nos jours. Bruxelles: Complexa, 1985.

GROMYKO, Andrei. Memoirs. New York: Doubleday, 1989(Foreword by Henry Kissinger). 
HALLIDAY, Fred. Génesis de la Segunda Guerra Fría. Mexico: Fondo de Cultura Económica, 1989.

HOROWITZ, David. De Yalta au Vietnam. Paris : Union Générale D’Éditions, 1973. 2 vols. KISSINGER, Henry. Diplomacy. New York: Simon \& Shuster, 1994.

LEVESQUE, Jacques. L'URSS et sa politique internationale. Paris: Armand Colin, 1980. SCHULZINGER, Robert. American diplomacy in the twentieth century. New York/Oxford: Oxford University Press, 1990.

STEEL, Ronald. Pax Americana. Barcelona: Lumen, 1970.

THOMPSON, Roger C. The Pacific Basin since 1945. London/New York, 1994.

VARAS, Augusto. De la Komintern a la Perestroika: America Latina y la URSS. Santiago: FLACSO, 1991.

VIGEVANI, Tullo. Terceiro Mundo: conceito e história. São Paulo: Ática, 1990.

VIZENTINI, Paulo. Da Guerra Fria à crise (1945-89). Porto Alegre: Ed. UFRGS, 1996. . Relações Internacionais e desenvolvimento no Brasil: o nacionalismo

e a Política Externa Independente (1945-1964). Petrópolis: Vozes, 1995.

WILSON, H. S. African decolonization. London/New York: Edward Arnold, 1994.

Resumo

O Sistema de Yalta foi encarado de diferentes maneiras pelos diversos atores do sistema internacional. Este artigo procura explorar como o Sul, ou o Terceiro Mundo, percebeu-o. Yalta não constituía a divisão do mundo, mas da Europa, e a constituição de um conjunto de regras em que o Sul era mantido como periferia do bloco norte-americano, encobrindo portanto uma dimensão de antagonismo Norte-Sul. Contudo, para o Brasil e para a América Latina em geral, o lugar ocupado neste sistema era ainda mais subordinado e periférico que em outras regiões. Isto levou o Brasil e outros países a buscar uma diplomacia mais autônoma através do nacionalismo desenvolvimentista.

\section{Abstract}

Yalta System was percieved in different ways by distinct actors of the international system. This article analyses the South, or Third World, perception's of this system. For these countries, Yalta was not a division of the world, but a division of Europe and the establishment of a group of rules by which the South was 
kept within the American bloc's periphery, hiding an antagonistic North-South dimension. However, for Brazil (and Latin America in general), its place in this system was even more subordinated and peripheric than for other regions. This situation led Brazil and other countries to search for more autonomous diplomacy in the direction of a nationalism geared to development.

Palavras-chave: Sistema de Yalta; Terceiro Mundo; Política Externa Brasileira Key-words: Yalta System; Third World; Brazilian Foreign Policy 